\title{
Effect of Y Addition on the Semi-Solid Microstructure Evolution and the Coarsening Kinetics of SIMA AZ80 Magnesium Alloy
}

\author{
Qi Tang ${ }^{(D)}$, Hao Sun, Mingyang Zhou and Gaofeng Quan * \\ Key Laboratory of Advanced Technologies of Materials, Ministry of Education, School of Materials Science and \\ Engineering, Southwest Jiaotong University, Chengdu 610031, China; tangqi@my.swjtu.edu.cn (Q.T.); \\ suns_h@163.com (H.S.); 18782951516@163.com (M.Z.) \\ * Correspondence: quangf@swjtu.cn; Tel.: +86-139-8006-6985
}

Received: 18 July 2017; Accepted: 3 October 2017; Published: 6 October 2017

\begin{abstract}
Semi-solid feedstock of AZ80 magnesium alloy modified by trace rare-earth Y element $(0,0.2,0.4,0.8$ wt. \%) was fabricated by strain-induced melting activation (SIMA) in the form of extrusion and partial remelting. The effect of $\mathrm{Y}$ addition on the microstructure evolution of the extruded and isothermally heat treated alloy was observed by using an optical microscope (OM), scanning electron microscope (SEM), X-ray diffraction (XRD) and quantitative analysis. The results show that the $\mathrm{Y}$ addition can refine the microstructure and make the $\beta-\mathrm{Mg}_{17} \mathrm{Al}_{12}$ phases agglomerate. During the subsequent isothermal treatment at $570{ }^{\circ} \mathrm{C}$, the average solid grain size, shape factor and liquid fractions increased with the prolonged soaking time. The smaller spheroidal solid grains and larger shape factor were obtained in the semi-solid microstructure due to $Y$ addition. The coalescence and Ostwald ripening mechanism operated the coarsening process of solid grains simultaneously. The coarsening rate constants of AZ80M1 (0.2 wt. \% Y addition) of $164.22 \mu \mathrm{m}^{3} \cdot \mathrm{s}^{-1}$ was approximately four times less than the un-modified AZ80 alloy of $689.44 \mu \mathrm{m}^{3} \cdot \mathrm{s}^{-1}$. In contrast, the desirable semi-solid structure featured, with fine and well globular solid grains, an appropriate liquid fraction, and shape factor was achieved in AZ80M1 alloy treated at $570{ }^{\circ} \mathrm{C}$ for $20-30 \mathrm{~min}$.
\end{abstract}

Keywords: Mg-Al-Zn-Y magnesium alloy; SIMA; extrusion; semi-solid; microstructure evolution

\section{Introduction}

AZ80 is one of the most successful commercial magnesium alloys with high-performance and high-strength, which has already been applied in the fields of aerospace, high-speed railways and automobiles in recent years [1-3]. However, magnesium alloy exhibits poor plastic deformation at room temperature owing to the hexagonal close-packed (HCP) structure with a limited number of slip systems [4,5]. The semi-solid forming (SSF) process as a new technology provides an effective approach to manufacture magnesium alloy components with complex shapes and high-level mechanical properties [6,7]. Compared to conventional forging or casting forming, the SSF process can effectively resolve the problem of metallurgical defects, such as over-burn, surface crack, porosity, macro-segregation and shrinkage [8-10]. Simultaneously, this process has a significant number of advantages, such as the small forming resistance, the extension of service life of forming die, production of the exact size and complex structural components, low production costs, and so on. These merits mainly derive from the fact that semi-solid alloys have a non-dendritic microstructure [11,12].

The major issue with the SSF process is the preparation of semisolid slurry with an ideal thixotropic microstructure with fine non-dendritic grains and an appropriate volume fraction of globular solid grains distributed uniformly within the liquid matrix [13]. The mechanical or electromagnetic stirring processes, semi-solid isothermal heat treatment (SSIT) and strain-induced melting activation (SIMA) 
are some methods that may be used for semi-solid feedstock preparation. Compared to two other methods, the SIMA process could easily achieve a high quality semi-solid feedstock. This process mainly includes two steps, namely, cold or hot deformation and subsequent partial remelting in the semi-solid temperature range. It was reported from the previous literature that a more spherical structure in AZ91D alloy semisolid slurry was obtained by the compression pre-deformed process known as the SIMA process [14]. Many researchers also introduced severe plastic deformation (SPD) to be another effective SIMA approach for producing the semi-solid feedstock. Jiang et al. [15] investigated AZ61 magnesium alloy pre-deformed by equal channel angular extrusion (ECAE) before remelting activation. The results showed that the high-quality semisolid billets with fine and spherical solid particles can be successfully prepared by isothermally treating the ECAE-processed alloy. In addition, repetitive upsetting-extrusion (RUE) was employed by Xu et al. [16] as the SIMA process to AZ91D magnesium alloy; it was found that the subsequent semi-solid feedstock with an ideal structure contains highly spherical and homogeneous solid grains. However, these methods are hard to apply in industrial production due to complex operations. The extrusion process is a promising and easily controlled method to obtain fine grains. Furthermore, the coarse second phases with lower melting points in original microstructure can be effectively crushed. This may hasten the evolution of globular structure during the SSIT route, resulting in high-quality semi-solid feedstock with more spherical and smaller solid grains $[3,17]$.

The rare-earth elements (RE), such as neodymium $(\mathrm{Nd})$, gadolinium $(\mathrm{Gd})$ and yttrium $(\mathrm{Y})$, are frequently added to magnesium alloy to enhance mechanical properties or corrosion behavior remarkably [18-20]. By comparison, $\mathrm{Y}$ is light and one of the most effective RE elements to improve mechanical properties of magnesium alloys, especially for the mechanical properties at elevated temperatures, owing to its considerable amount of solubility in Mg alloys [21]. Therefore, this research is aiming at applying the extrusion process as the SIMA approach to trace Y added AZ80 magnesium alloy. Microstructure evolution of extruded alloys in solid state and partial remelting state are investigated. In addition, the effect of $Y$ addition on the coarsening kinetics of deformed AZ80 alloy during the isothermal treatment in the semi-solid range was examined.

\section{Materials and Methods}

Four different types of materials used in this study were based on AZ80 (Mg-8 wt. \% Al-0.5 wt. \% $\mathrm{Zn}$ ) alloy. Inductively Coupled Plasma-Atomic Emission Spectrometer (ICP-AES, NCS Testing Technology Co., Ltd. Beijing, China) was used to examine the chemical composition, and the results are listed in Table 1. The pure magnesium (99.9 wt. \%), pure aluminum (99.9 wt. \%), pure zinc (99.9 wt. \%), and Mg-30 wt. \% Y master alloy were melted in electric resistance furnace protected by $\mathrm{CO}_{2}+2$ vol. $\%$ $\mathrm{SF}_{6}$ mixed gas. The molten alloy was held at $720^{\circ} \mathrm{C}$ for $40 \mathrm{~min}$ to ensure that yttrium was completely dissolved and then smoothly poured into the steel mould with a diameter of $95 \mathrm{~mm}$. Subsequently, the billets were homogenized at $420^{\circ} \mathrm{C}$ for $12 \mathrm{~h}$ to eliminate the dendritic crystal structure. Then, these billets were machined into columnar bars with a diameter of $90 \mathrm{~mm}$. Prior to extrusion, the ingots and extrusion die were preheated to $350{ }^{\circ} \mathrm{C}$ and maintained for $1 \mathrm{~h}$. The oil-based graphite lubricant was used to reduce friction between the die and ingot. Finally, the rods with a diameter of $16 \mathrm{~mm}$ were extruded at a speed of $15 \mathrm{~mm} \cdot \mathrm{s}^{-1}$ with an extrusion ratio of about 32:1.

The extrusion bars were machined into the samples with a diameter of $10 \mathrm{~mm}$ and a height of $10 \mathrm{~mm}$. These cylindrical samples were reheated to $570{ }^{\circ} \mathrm{C}$, with an accuracy of $\pm 2{ }^{\circ} \mathrm{C}$, and maintained for 5, 10, 20, $30 \mathrm{~min}$. Then, the samples were quenched in water immediately after the isothermal treatment. 
Table 1. Chemical composition of experimental alloys (wt. \%).

\begin{tabular}{cccccc}
\hline Alloy & & Mg & Al & Zn & Y \\
\hline \multirow{2}{*}{ AZ80 } & 1 & Bal. & 8.0 & 0.5 & 0 \\
& 2 & Bal. & 8.701 & 0.491 & 0 \\
AZ80M1 & 1 & Bal. & 8.0 & 0.5 & 0.2 \\
& 2 & Bal. & 8.384 & 0.508 & 0.242 \\
AZ80M2 & 1 & Bal. & 8.0 & 0.5 & 0.4 \\
& 2 & Bal. & 8.467 & 0.528 & 0.437 \\
AZ80M3 & 1 & Bal. & 8.0 & 0.5 & 0.8 \\
& 2 & Bal. & 7.716 & 0.480 & 0.829 \\
\hline \multicolumn{5}{c}{${ }^{1}$ nominal composition; ${ }^{2}$ real composition. }
\end{tabular}

Microstructure of the extruded and semi-solid specimens was observed by using Zeiss Lab. A1 optical metallographic (OM, ZEISS, Oberkochen, Germany) and Quanta FEG 250 scanning electron microscope (SEM, FEI, Hillsboro, OR, USA) at a voltage of $20 \mathrm{kV}$. Samples for metallographic and SEM analysis were ground, mechanically polished and etched in a solution of $1 \mathrm{~g}$ oxalic acid, $1 \mathrm{~mL}$ acetic acid, $1 \mathrm{~mL}$ nitric acid and $150 \mathrm{~mL}$ distilled water. The phase composition of the as-extruded alloys was identified by X-ray diffraction (XRD) analysis using Panalytical X'Pert Pro (PANalytical B.V., Almelo, Holland) with $\mathrm{Cu} \mathrm{K} \alpha_{1}$ radiation $(\lambda=0.154 \mathrm{~nm})$ with the scanning angle range from 20 to 80 degrees, and the reflecting surface was perpendicular to the extrusion direction. The average grain size was determined by the linear intercept method for at least three pictures blindly selected and widely separate fields. Quantitative analysis of the micrographs of the specimens in the semi-solid state were carried out using Image-Pro Plus software (Media Cybernetics Company, Sliver Spring, $\mathrm{MD}, \mathrm{USA}$ ) and the statistical results of solid fraction and shape factor were determined by three $\mathrm{OM}$ images. The shape factor of solid particles was calculated by the following equation [22]:

$$
F_{s}=\frac{1}{n} \sum_{n=1}^{n} \frac{4 \pi A_{n}}{P_{n}^{2}}
$$

where $F_{S}$ is the shape factor; $n$ is the number of solid particles; $A$ is the area of solid particles; and $P$ is the perimeter of solid particles.

\section{Results and Discussion}

\subsection{Microstructure of As-Extruded Alloy}

Figure 1 shows the microstructures of the as-extruded AZ80 magnesium alloy with different $Y$ contents on the transverse section perpendicular to the extrusion direction (ED). It can be seen that $Y$ had a remarkable effect on grain refinement. Figure 1a shows the as-extruded AZ80 without $Y$ addition. The microstructure consists of equiaxed grains, and the average grain size is about $23.63 \pm 2.52 \mu \mathrm{m}$. As is well known, the dynamic recrystallization (DRX) behavior is the dominant mechanism for refining $\alpha-\mathrm{Mg}$ matrix grains during the hot extrusion process [23]. Some new fine grains were formed at the original grain boundaries to form a typical necklace structures. As the $\mathrm{Y}$ contents increased to $0.2 \mathrm{wt}$. \%, the fine grains $(\sim 15.94 \pm 0.98 \mu \mathrm{m})$ were obtained, but some coarse ones $(\sim 22.54 \mu \mathrm{m})$ can also be found in Figure $1 \mathrm{~b}$. When the addition of $Y$ further increased to 0.4 and $0.8 \mathrm{wt}$. \%, as was observed in Figure 1c,d, the bimodal microstructure was more obvious, which consists of relatively coarse DRX grains and fine DRX grains. However, the average grain sizes changed a little, corresponding to $9.74 \pm 0.68 \mu \mathrm{m}, 9.31 \pm 0.34 \mu \mathrm{m}$ approximately. The XRD pattern of the as-extruded AZ80 magnesium alloy with different amounts of $Y$ addition is shown in Figure 2. Three kinds of phases can be detected in these alloys, which are $\alpha-\mathrm{Mg}, \beta-\mathrm{Mg}_{17} \mathrm{Al}_{12}$ and $\mathrm{Al}_{2} \mathrm{Y}$, respectively. 

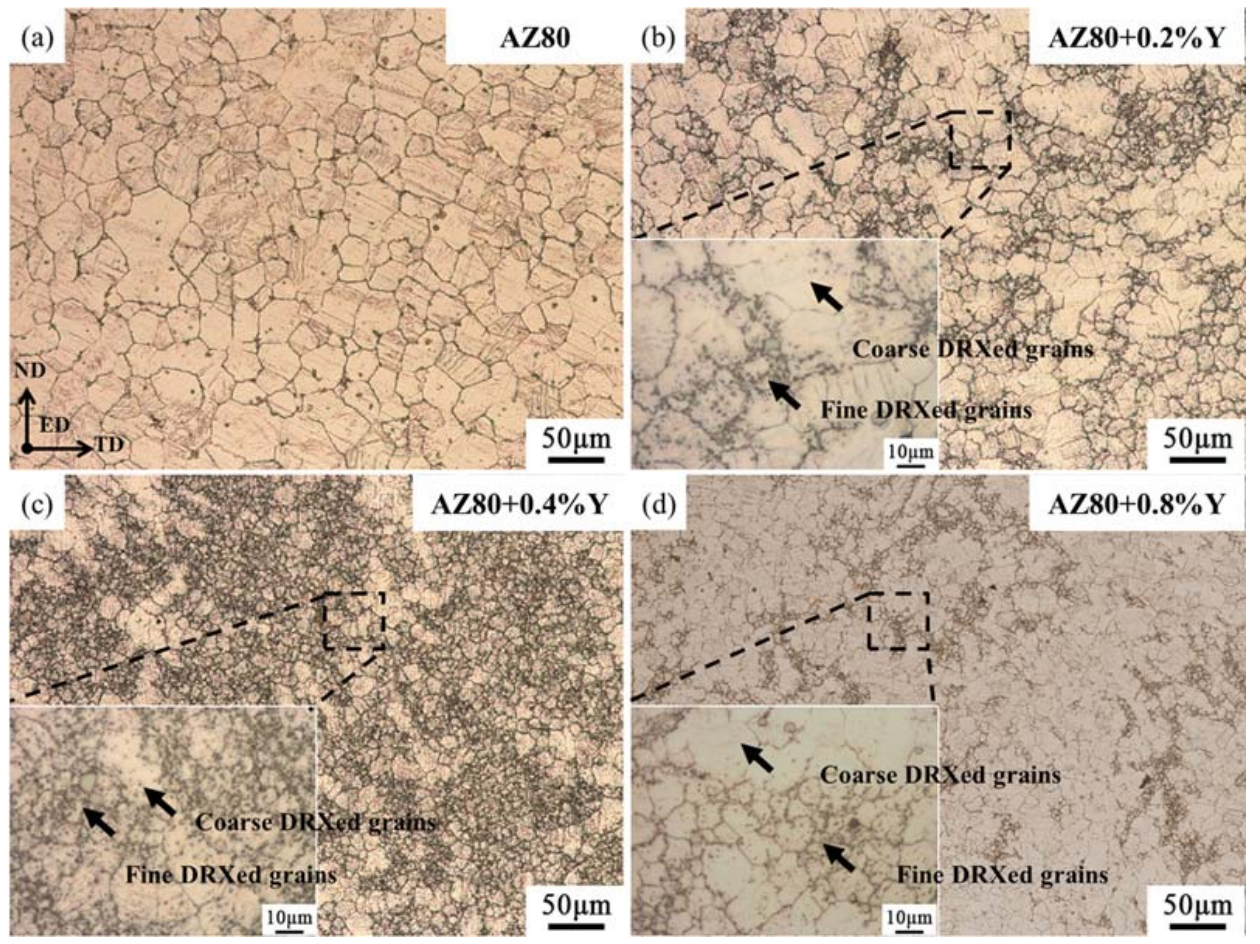

(d)
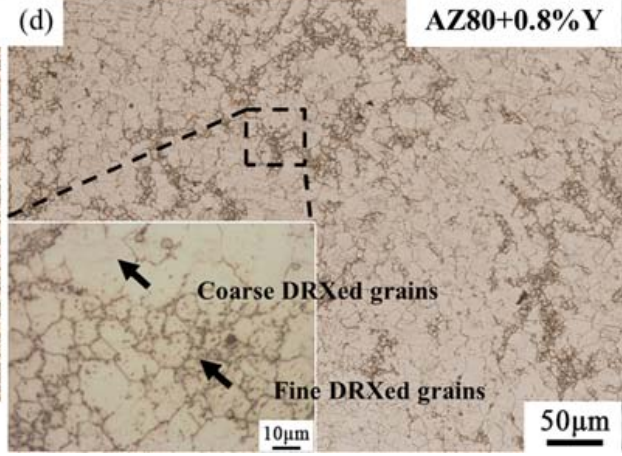

Figure 1. Microstructure of the extruded alloys: (a) AZ80; (b) AZ80M1; (c) AZ80M2; and (d) AZ80M3.

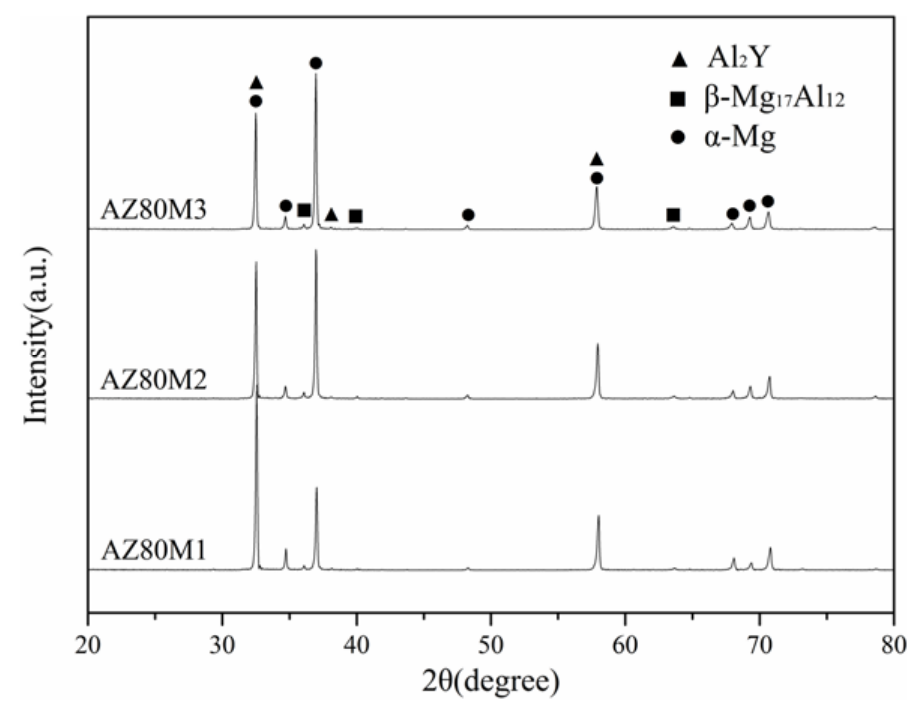

Figure 2. XRD patterns of AZ80 magnesium alloys with different $Y$ contents.

The $\beta-\mathrm{Mg}_{17} \mathrm{Al}_{12}$ and $\mathrm{Al}_{2} \mathrm{Y}$ phases of the as-extruded $\mathrm{AZ} 80$ magnesium alloy with different $\mathrm{Y}$ additions are shown in Figure 3. As can be observed in Figure 3a, the AZ80 magnesium alloy only consists of $\alpha-\mathrm{Mg}$ matrix and $\beta-\mathrm{Mg}_{17} \mathrm{Al}_{12}$ (marked with the red arrows). Compared to the alloy containing $\mathrm{Y}$ (seen from Figure $3 \mathrm{~b}-\mathrm{d}$ ), the $\beta-\mathrm{Mg}_{17} \mathrm{Al}_{12}$ was relatively larger and the size was between $1.8 \mu \mathrm{m}$ and $2.5 \mu \mathrm{m}$ assumably, which was mainly distributed evenly in the $\alpha-\mathrm{Mg}$ matrix as a semi-continuous network along the grain boundaries or dispersive particles within the $\alpha-\mathrm{Mg}$ matrix. After the addition of $\mathrm{Y}$, as shown in Figure $3 \mathrm{~b}-\mathrm{d}$, the network $\beta-\mathrm{Mg}_{17} \mathrm{Al}_{12}$ phases decreased, and a large amount of them were transformed into more tiny granulous precipitates with the mean size less than $1.5 \mu \mathrm{m}$. Meanwhile, the irregular and blocky $\mathrm{Al}_{2} \mathrm{Y}$ precipitates appeared, which were about 10 times larger than $\beta-\mathrm{Mg}_{17} \mathrm{Al}_{12}$ particles (marked with yellow arrows). It was 
noteworthy that lots of fine granulous $\beta-\mathrm{Mg}_{17} \mathrm{Al}_{12}$ particles tended to agglomerate due to the dynamic precipitation process from the supersaturated $\alpha-\mathrm{Mg}$ matrix, as represented in Figures $1 \mathrm{~b}-\mathrm{d}$ and $3 \mathrm{~b}-\mathrm{d}$. The inhomogeneous distribution of $\beta-\mathrm{Mg}_{17} \mathrm{Al}_{12}$ phases increased with the addition of $\mathrm{Y}$. Around the precipitation agglomeration regions, a large number of newly formed DRX grains can be found and the sub-micron precipitations were distributed more widely at the boundaries of DRX grains. This is consistent with the findings of Guo et al. [2], Huang et al. [24], and Zhu et al. [25] for the investigation of the large strain hot rolling processed Mg-8Al alloy sheets, extrusion processed AZX912 alloy and multi-directional forging (MDF) processed AZ80 alloy, respectively. They all observed the dynamic precipitation, and eventually the granular and inhomogeneous distribution $\beta-\mathrm{Mg}_{17} \mathrm{Al}_{12}$ phase caused the formation of the coarse-grain and fine-grain zones. These phenomena can be attributed to the following two main reasons: (i) the fine $\beta-\mathrm{Mg}_{17} \mathrm{Al}_{12}$ particles may assist the particle stimulating nucleation (PSN) mechanism [26] to induce more nucleation of $\alpha-\mathrm{Mg}$ grains at the interfaces of particles; (ii) these refinement particles could inhibit and suppress the growth of newly formed DRX grains during the hot deformation process because the $\beta-\mathrm{Mg}_{17} \mathrm{Al}_{12}$ phases mainly precipitated at grain boundaries; in other words, these boundaries were pinned by these phases, resulting in difficult migration.
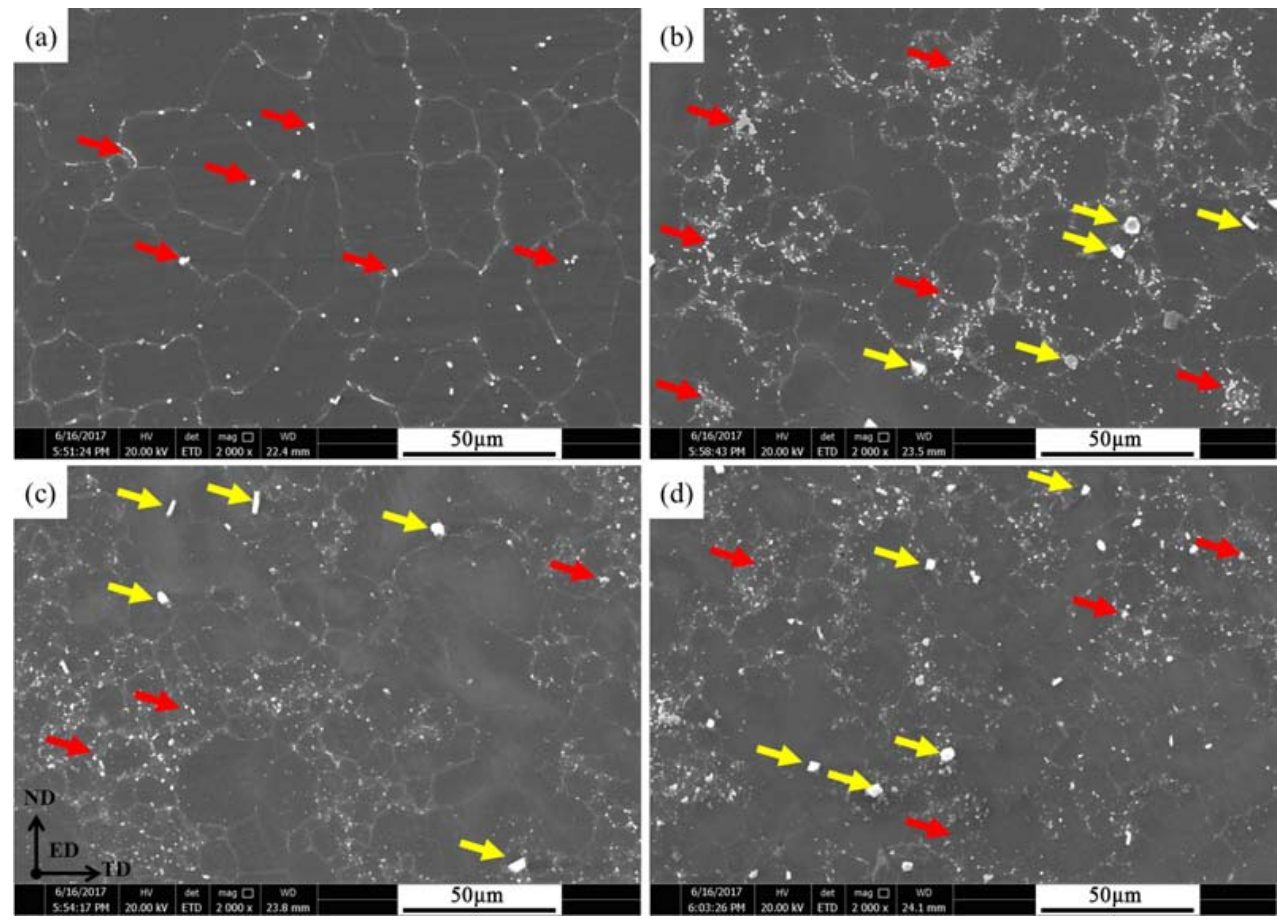

Figure 3. SEM images of the as-extruded alloys: (a) AZ80; (b) AZ80M1; (c) AZ80M2; and (d) AZ80M3. $\left(\beta-\mathrm{Mg}_{17} \mathrm{Al}_{12}\right.$ phase marked with the red arrow; $\mathrm{Al}_{2} \mathrm{Y}$ phase marked with the yellow arrow).

\subsection{Effect of Y Addition on the Microstructure Evolution during Isothermal Treatment}

Figures 4-7 illustrate the microstructure evolution of the as-extruded AZ80, AZ80M1, AZ80M2 and AZ80M3 alloy after soaking at $570{ }^{\circ} \mathrm{C}$ for different times, respectively. Compared with AZ80 alloy, it was clarified that the $\mathrm{Y}$ added samples have a vast number of spheroidal solid grains. The sizes of intragranular liquid droplets also increased obviously as the $\mathrm{Y}$ addition increased and the isothermal soaking time prolonged from $5 \mathrm{~min}$ to $30 \mathrm{~min}$. Moreover, the size of globular solid particles and liquid fraction increased as well. Concerning the micrographs in Figure 4, the solid particles with polygonous boundaries were distributed unevenly in the semi-solid slurry and more fine and dense liquid droplets were formed within $\alpha-\mathrm{Mg}$ grains. Meanwhile, some smaller solid particles were discovered between the adjacent larger solid crystals. It was noteworthy that a quite inhomogeneous microstructure 
appeared in all three of the RE added alloys when the isothermal treatment was conducted at $570{ }^{\circ} \mathrm{C}$ for $5 \mathrm{~min}$ (as indicated by red arrows in Figure $4 \mathrm{~b}-\mathrm{d}$ ) because the liquid phase was not infiltrated along the boundaries. This was similar to the investigation of the microstructure evolution during reheating of the extruded $\mathrm{Mg}-\mathrm{Al}-\mathrm{Zn}$ alloy by Kleiner et al. [17]. As is well known, the initial liquid phase mainly originated from the melting of some low-melting point precipitates, which occurred at the triple points of grain boundaries firstly. With the partial remelting further developing, the liquid phases started infiltrating along the grain boundaries and the intragranular liquid droplets also appeared. Combined with the phase distribution depicted in Figures 1 and 3, the varying degrees of $\beta-\mathrm{Mg}_{17} \mathrm{Al}_{12}$ precipitation agglomeration appeared in the $\mathrm{Y}$ added alloys. This phenomenon may lead to the non-uniform distribution of $\mathrm{Al}$ in the matrix, leading to the formation of Al-rich regions and Al-poor regions. According to the Mg-Al binary alloy phase diagram [27], the solidus temperature decreased with increasing $\mathrm{Al}$ contents below $12 \mathrm{wt}$ \%. Thus, the remelting behavior may start at Al-rich regions and no grain boundaries were wetted in the Al-poor areas when the temperature was below the solidus temperature, which could account for the inhomogeneous remelting microstructure at grain boundaries illustrated in Figure $4 \mathrm{~b}-\mathrm{d}$. In summary, the segregation of $\beta-\mathrm{Mg}_{17} \mathrm{Al}_{12}$ phases evidently influenced the semi-solid microstructure in the early stage of partial remelting.
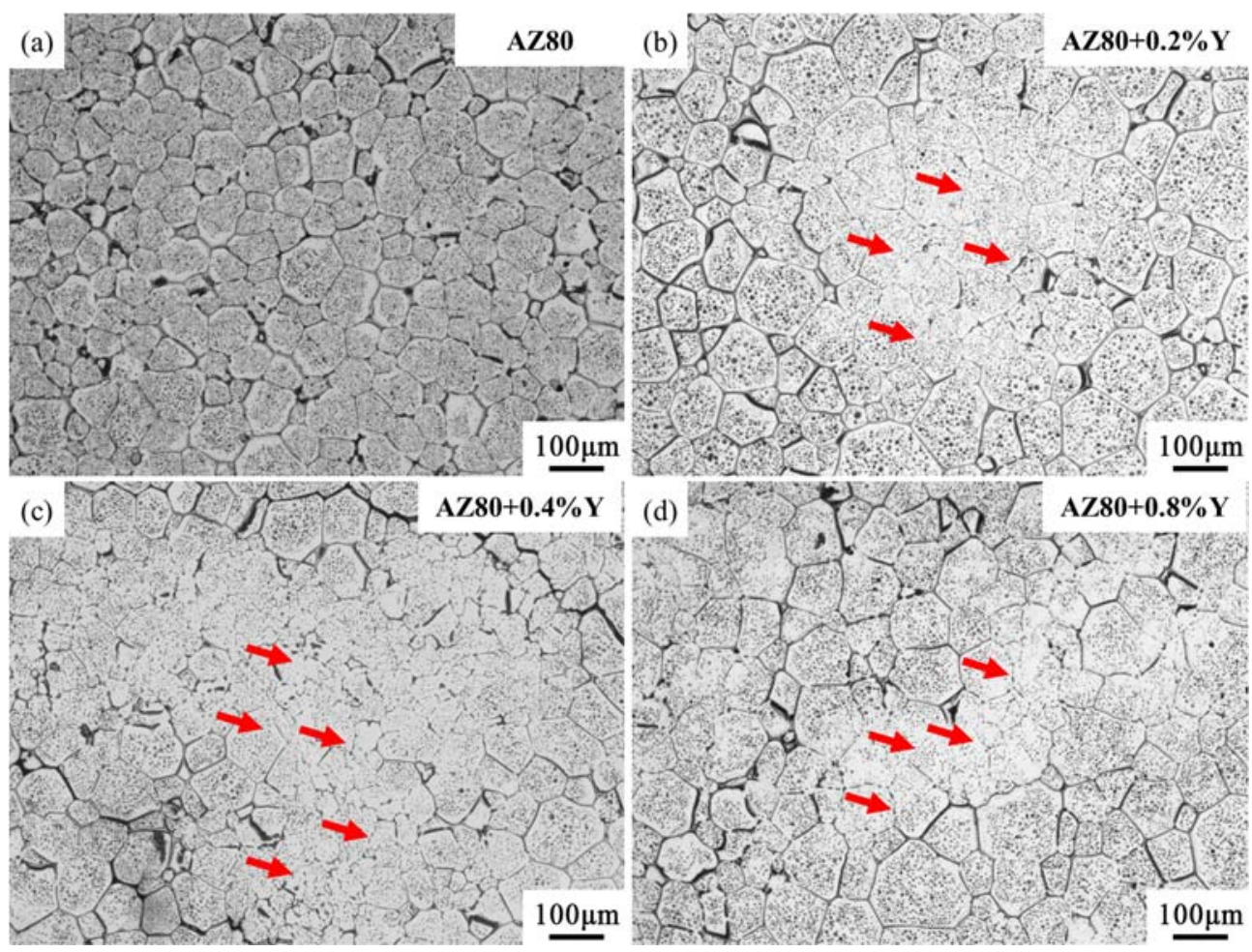

Figure 4. Microstructure evolution of alloys isothermally treated at $570{ }^{\circ} \mathrm{C}$ holding for $5 \mathrm{~min}$ : (a) AZ80; (b) AZ80M1; (c) AZ80M2; and (d) AZ80M3. (Inhomogeneous remelting regions are marked with the red arrows).

Continuing to increase the holding time to $10 \mathrm{~min}$, as shown in Figure 5, the size of the majority of solid particles became bigger in all alloys as a result of the Oswald ripening mechanism or the coalescence of two adjacent solid grains, and the former was considered as the dominant coarsening mechanism generally [11,28]. Furthermore, the liquid droplets within solid crystals transformed to the suborbicular liquid pools with the size from 10 to $20 \mu \mathrm{m}$, and the liquid films between solid $\alpha$-Mg also became thicker in AZ80 alloy modified by Y elements. However, some inhomogeneous microstructure regions were also found in AZ80M2 (as indicated by red arrows) in Figure 5c. This was attributed to severe $\beta-\mathrm{Mg}_{17} \mathrm{Al}_{12}$ phase agglomeration in the extruded corresponding alloy in Figure 1c. 

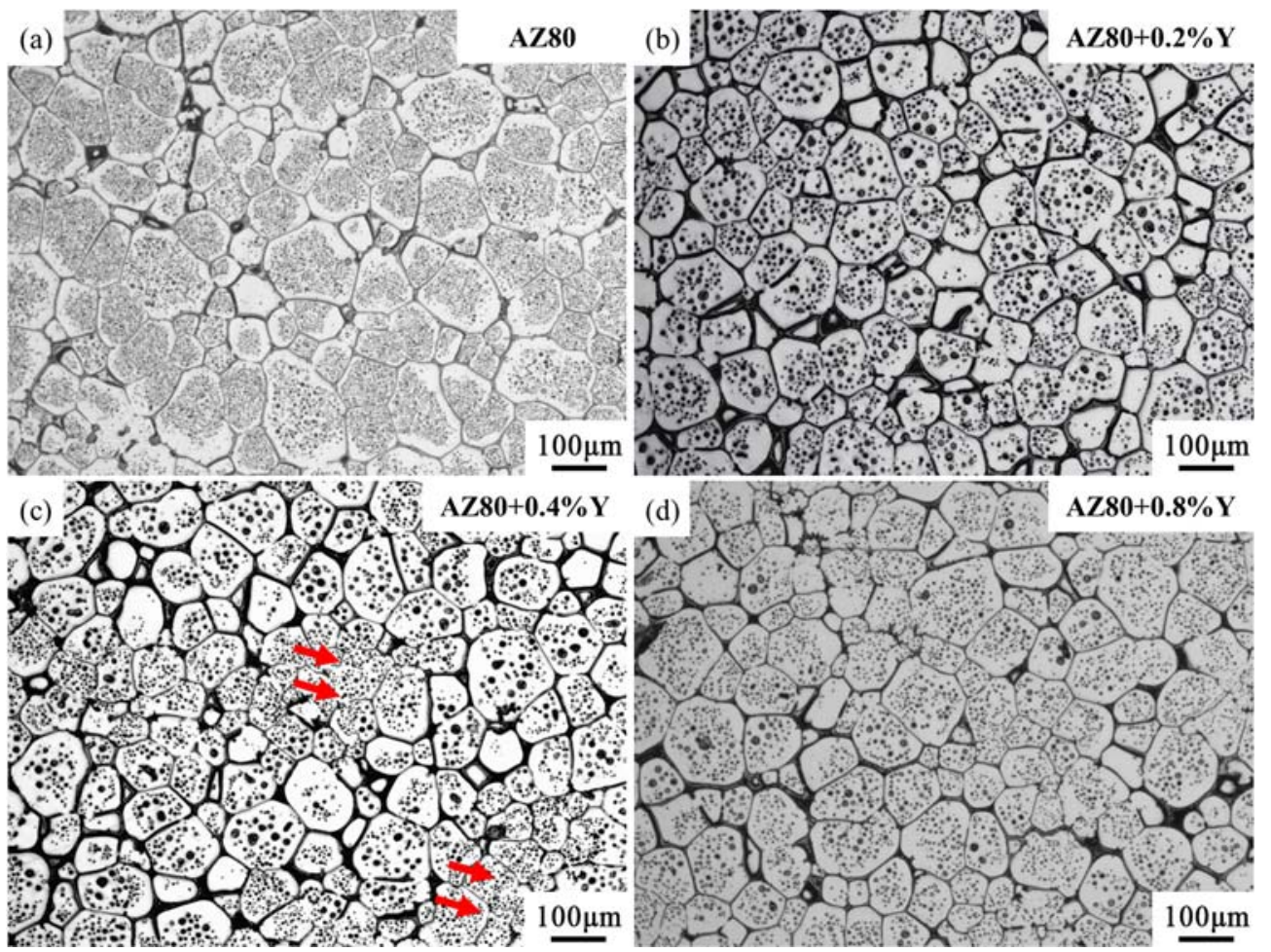

Figure 5. Microstructure evolution of alloys isothermally treated at $570{ }^{\circ} \mathrm{C}$ holding for $10 \mathrm{~min}$ : (a) AZ80; (b) AZ80M1; (c) AZ80M2; and (d) AZ80M3.
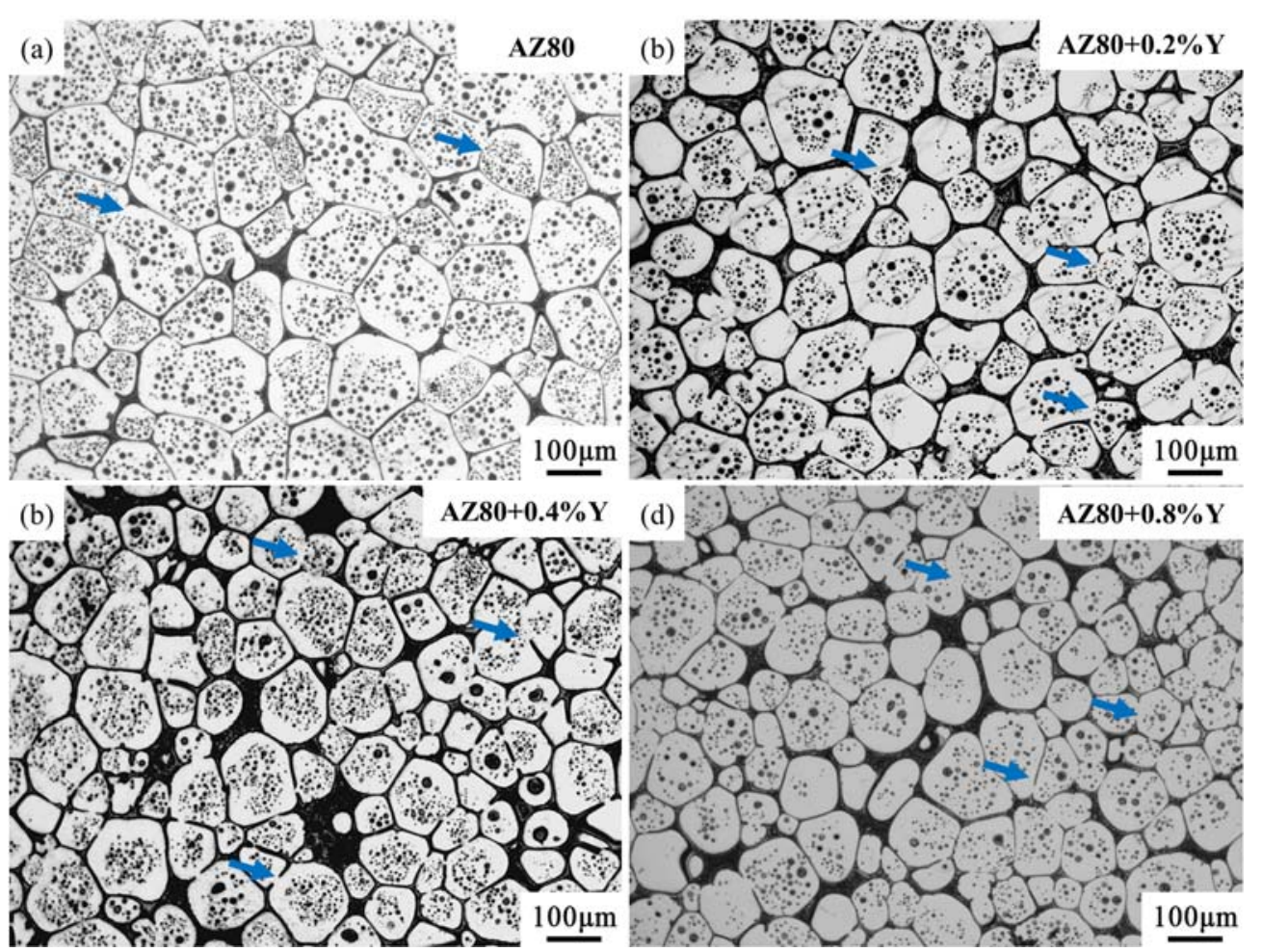

Figure 6. Microstructure evolution of alloys isothermally treated at $570{ }^{\circ} \mathrm{C}$ holding for $20 \mathrm{~min}$ : (a) AZ80; (b) AZ80M1; (c) AZ80M2; and (d) AZ80M3. 
Further prolonging the isothermal time to $20 \mathrm{~min}$, as seen in Figure 6, the average grain size and globularity of solid particles increased distinctly. Meanwhile, the liquid films between solid particles became much thicker and more continuous after $Y$ addition. However, a decrease in the number of intragranular liquid droplets was exhibited. A few solid particles lower than the average grain size also existed, which can be attributed to the Ostwald ripening mechanism [13]. This process involved the diameter of the bigger grains increasing at the expense of the smaller ones during the partial remelting. It can be seen that some adjacent solid grains were interconnected to form bigger ones, as indicated by blue arrows in Figure 6. This was also demonstrated by Xu et al. [16] and Chen et al. [29] for the research on the semi-solid microstructure evolution of RUE-formed and ECPA-formed AZ91D alloy, and they suggested that the Ostwald ripening mechanism and the coalescence of solid particles operated simultaneously and independently for the grain coarsening.

When the soaking time extended to $30 \mathrm{~min}$ (Figure 7), it can be observed that the size and sphericity of solid $\alpha$-Mg were further increased. Moreover, a small number of larger and more globular liquid pools gathered in the core region of solid particles in all alloys to minimize the system's total surface area according to the energy theory $[16,20]$. The higher the liquid fraction is, the smaller the probability of the coalescence of solid grains. Therefore, the Ostwald ripening mechanism became the dominant mechanism for grain growth after a long time holding at $570{ }^{\circ} \mathrm{C}$, owing to more atoms diffusing in the melted regions along the liquid phase. In contrast, AZ80 with the addition of 0.2 wt. \% $\mathrm{Y}$ obtained the desired structure with a finer solid grain size and was uniform in the shape of $\alpha-\mathrm{Mg}$ and the thickness of liquid films.
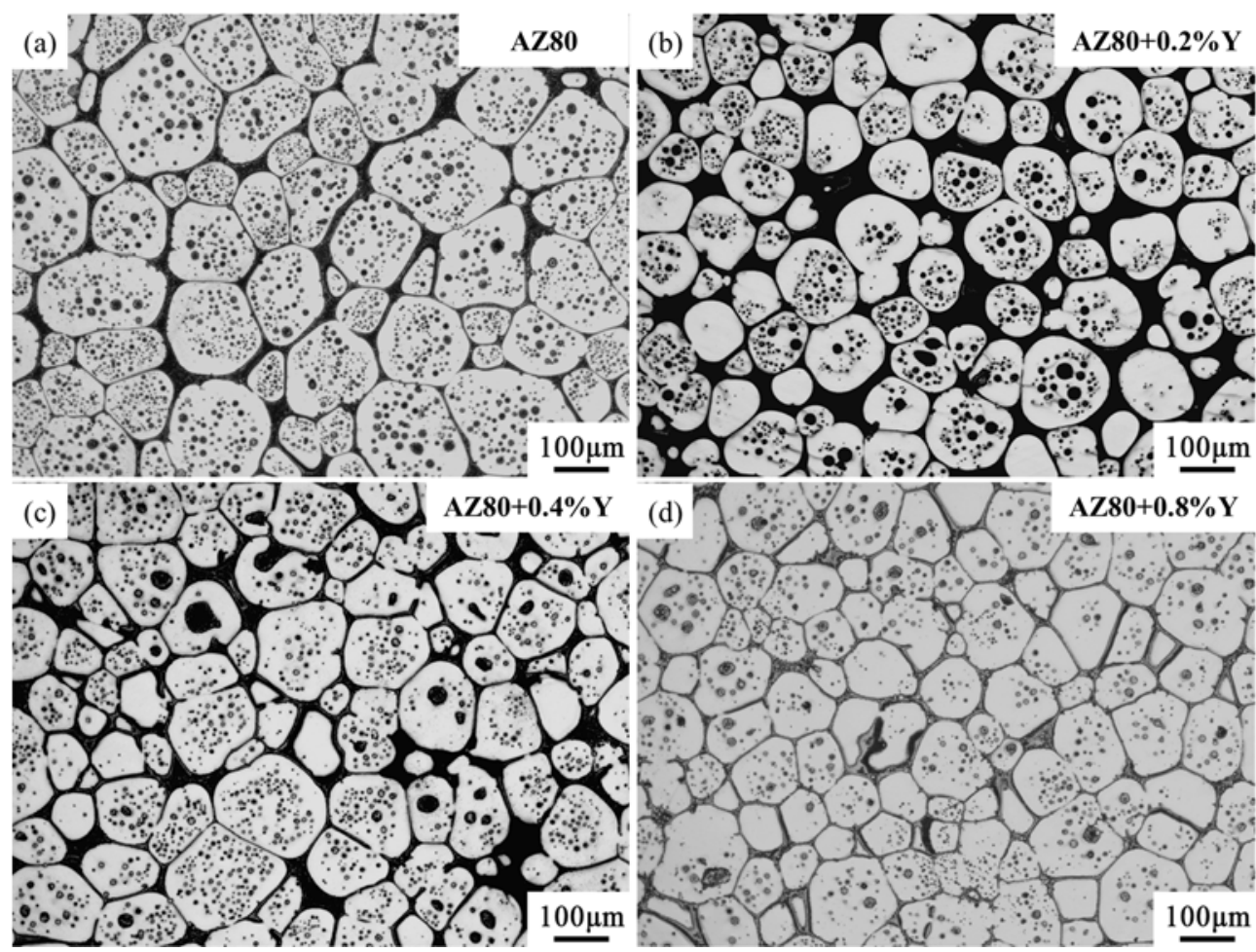

Figure 7. Microstructure evolution of alloys isothermally treated at $570{ }^{\circ} \mathrm{C}$ holding for $30 \mathrm{~min}$ : (a) AZ80; (b) AZ80M1; (c) AZ80M2; and (d) AZ80M3.

\subsection{Shape Factor, Average Solid Grain Size and Solid Fraction of the Alloys}

The shape factor and average grain size of solid particles are shown in Figures 8 and 9, respectively. As treated for $5 \mathrm{~min}, 10 \mathrm{~min}, 20 \mathrm{~min}$ and $30 \mathrm{~min}$, both the shape factor and average solid grain size gradually increased during the isothermal holding at $570^{\circ} \mathrm{C}$. These results indicated that the coarsening and spheroidization were introduced by the prolonging soaking time. However, the average solid 
grain size of the Y-containing alloys was demonstrated to be a little bigger than the AZ80 alloy when the time was no more than $10 \mathrm{~min}$, which could be attributed to the $\beta-\mathrm{Mg}_{17} \mathrm{Al}_{12}$ phase segregation and resulted in grains without clear boundaries during the initial stage of isothermal treatment. Furthermore, not only the shape factor but also the average solid grain size in AZ80M alloy was lower than the unmodified ones. It can be concluded that the rare-earth $Y$ element was valid for refining the microstructure of semi-solid magnesium alloy. In other words, the growth of solid particles has been excessively restricted by adding the rare earth $\mathrm{Y}$ element.

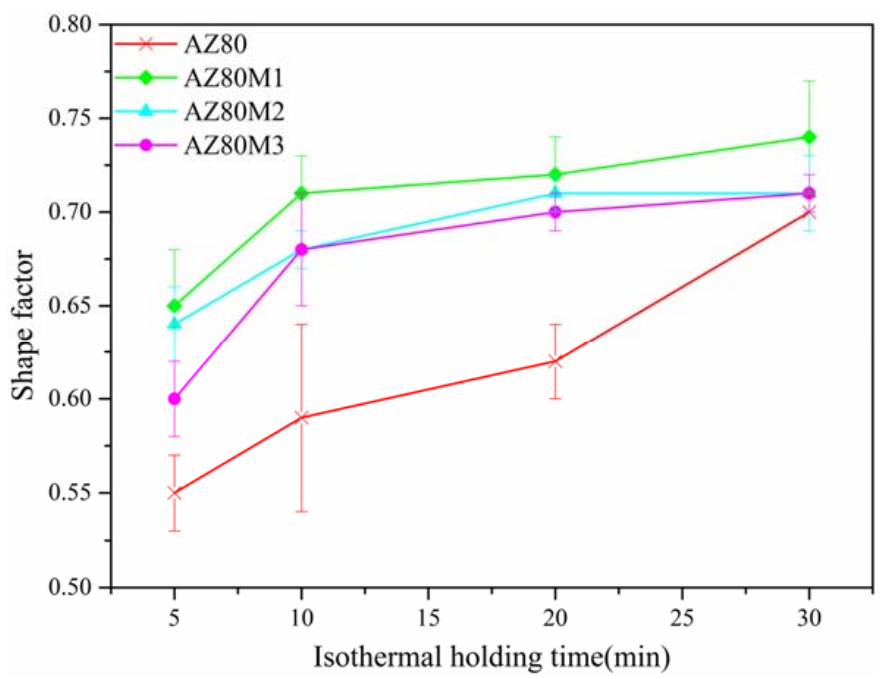

Figure 8. Effect of $\mathrm{Y}$ addition on the shape factor at $570{ }^{\circ} \mathrm{C}$ for different isothermal holding times.

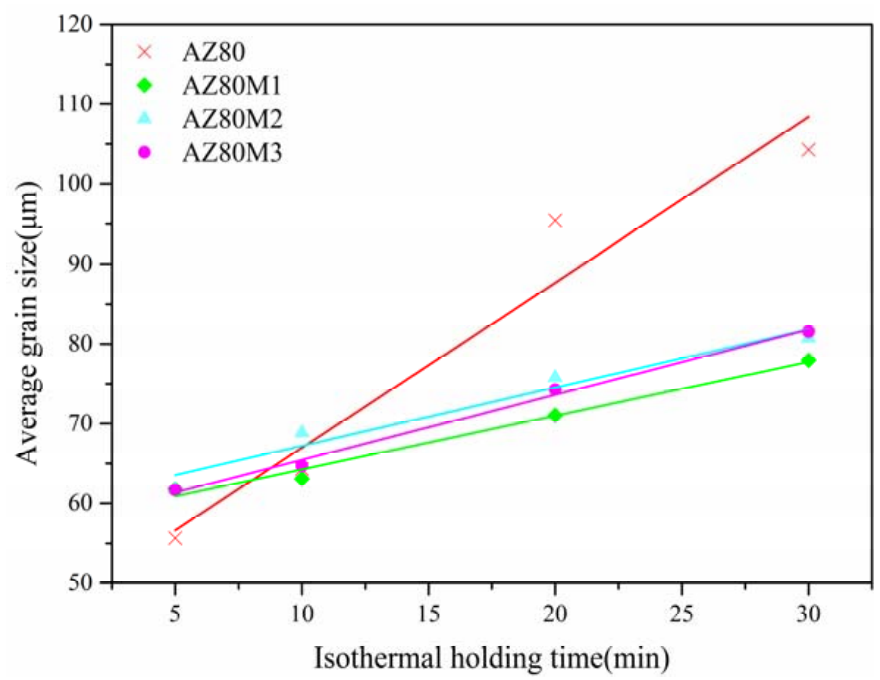

Figure 9. Effect of $\mathrm{Y}$ addition on the average solid grain size at $570{ }^{\circ} \mathrm{C}$ for different isothermal holding times.

The solid fraction of the alloys is presented in Table 2. The solid volume fraction varied in the range from 0.69 to 0.81 and increased with the prolonging isothermal soaking time from 5 min to $30 \mathrm{~min}$. It was revealed that the semi-solid slurry with a high solid fraction between 0.75 and 0.8 had the better thixotropic behavior [6,22]. Moreover, the forming defects such as porosity, inclusions or shrinkage could be visibly prevented in the high solid fraction semi-solid feedstock during the forming process. However, the lower globularization of solid particles was unfavorable for the thixotropic behavior $[8,14]$. Therefore, it is expected that the AZ80 modified by $0.2 \mathrm{wt}$. \% Y may be deemed as the 
optimal semi-solid slurry to achieve the thixotropic applications on the basis of the smaller solid grain size, the larger shape factor and an appropriate solid fraction.

Table 2. Solid fraction of the experimental alloys at $570{ }^{\circ} \mathrm{C}$ for various isothermal times.

\begin{tabular}{ccccc}
\hline Alloy & $\mathbf{5} \mathbf{~}$ in & $\mathbf{1 0} \mathbf{~} \mathbf{i n}$ & $\mathbf{2 0} \mathbf{~}$ in & $\mathbf{3 0 ~} \mathbf{~ i n}$ \\
\hline AZ80 & 0.81 & 0.75 & 0.70 & 0.69 \\
AZ80M1 & 0.80 & 0.74 & 0.72 & 0.71 \\
AZ80M2 & 0.77 & 0.72 & 0.69 & 0.69 \\
AZ80M3 & 0.80 & 0.75 & 0.69 & 0.69 \\
\hline
\end{tabular}

\subsection{Spheroidization and Coarsening Mechanisms of Semi-Solid Microstructure}

The Oswald ripening governed by the Gibbs-Thompson effect have been widely reported by many researchers $[5,30]$, which altered the solute atomic concentration at the solid particles interface depending on the curvature of the solid-liquid interface, according to the Gibbs-Thompson formula expressed by the following expression:

$$
C_{\alpha}(r)=C_{\alpha}(\infty) \exp \left(\frac{2 \sigma V_{B}}{k_{B} T r}\right)
$$

where $C_{\alpha}(r)$ is the solute atom concentration at the site with a curvature radius $r ; C_{\alpha}(\infty)$ is the solute atom concentration at a flat interface; $\sigma$ is the surface tension; $V_{B}$ is the volume of atom; $T$ is the temperature and $k_{B}$ is the shape coefficient.

According to Equation (2), the smaller the curvature radius $r$ is, the higher the atom concentration will be. Generally, the different positions of solid particles have a different curvature radius due to an irregular shape, which causes a gradient of atom concentration between these areas. During the isothermal soaking treatment, the atoms will diffuse from the relatively larger curvature where the atom concentration is high to the flat interface where the atom concentration is low, so the balance of atom concentration is broken. Therefore, the sites with larger curvature would be dissolved to keep the balance of atom concentration. Then, the suborbicular or spherical solid $\alpha$-Mg was formed.

Subsequently, the Gibbs free energy $(\Delta G)$ of a single grain under a function of the interface curvature and the solid-liquid interfacial energy can be expressed by the following expression:

$$
\Delta G=2 \gamma \frac{\Delta V}{r}
$$

where $r$ and $\gamma$ are the average curvature radius and interfacial energy of the solid-liquid interface in the semisolid slurry, respectively; $\Delta V$ is the variation molar volume.

The Gibbs free energy $(\Delta G)$ could serve as the driving force for the grains' growth [11]. The solid $\alpha-\mathrm{Mg}$ particles adjusted by the Oswald ripening mechanism could be considered as having the similar curvature radius and molar volume owing to the suborbicular or spherical shape. Previous literature $[20,29,31]$ has concluded that the rare earth elements were surface-active elements and they could decrease the surface energy of the alloys melt, resulting in reducing the solid-liquid interfacial energy. Therefore, the value of $\Delta G$ decreased due to the reduction of the solid-liquid interfacial energy by adding a $Y$ element. Moreover, the inadequate and discontinuous liquid films occurred in the initial stage of partial remelting. It was reported that two solid $\alpha$-Mgs merged only when the interfacial energy between the solid and liquid phase $\left(\gamma_{\mathrm{sl}}\right)$ was bigger than the interfacial energy between the solid particles $\left(\gamma_{\mathrm{ss}}\right)$ [32]. However, the decreasing of $\gamma_{\mathrm{sl}}$ caused by $\mathrm{Y}$ addition has been difficult to satisfy the condition of $\gamma_{\mathrm{sl}}>\gamma_{\mathrm{ss}}$. Thus, the coalescence of the solid $\alpha$-Mg was sharply hindered. Therefore, it can be concluded the comprehensive effect of the reduction of Gibbs free energy $(\Delta G)$ and the decreasing probability of coalescence of adjacent solid $\alpha-\mathrm{Mg}$ particles make the spherical structure with relatively finer grain size in the semi-solid slurry of AZ80 alloy modified by the RE element. 


\subsection{Coarsening Kinetics of the Alloys}

During the isothermal soaking process, the coarsening of solid particles is mainly controlled by the Ostwald ripening mechanism. The coarsening kinetics can be described by the classical Lifshitz-Slyozov-Wagner (LSW) equation [33]:

$$
D^{n}-D_{0}^{n}=k t,
$$

where $D$ is the final average grain size; $D_{0}$ is the initial average grain size; $t$ is the isothermal holding time; $k$ is the coarsening rate constant; and $n$ is the power exponent. It was believed that an $n$ value of 3 is suitable for investigating the volume diffusion-controlled coarsening in the semi-solid state during partial remelting $[9,12]$.

The cube of experimental results of the average solid grain sizes as a function of the isothermal holding time for the as-extruded AZ80 containing different $Y$ contents at $570{ }^{\circ} \mathrm{C}$ is plotted in Figure 10 . The value of $D_{0}$ was the average grain size when the soaking time was $5 \mathrm{~min}$ in this paper. It can be confirmed that the coarsening kinetics of all the four kinds of alloys during the isothermal heating had the best correlation with Equation (4). This was determined by the regression coefficient $\left(R^{2}\right)$ of the fitted straight lines all close to 1 . The values of $k$ obtained from the slope of fitted lines in Figure 10 were $689.44 \mu \mathrm{m}^{3} \cdot \mathrm{s}^{-1}, 164.22 \mu \mathrm{m}^{3} \cdot \mathrm{s}^{-1}, 192.45 \mu \mathrm{m}^{3} \cdot \mathrm{s}^{-1}$ and $211.16 \mu \mathrm{m}^{3} \cdot \mathrm{s}^{-1}$ in AZ80, AZ80M1, AZ80M2 and AZ80M3 alloy, respectively. It was shown that the coarsening rate was significantly slower by adding a Y element due to the reduction of the solid-liquid interfacial energy. In addition, it was clearly noticed that the minimum $k$ value achieved in the extruded AZ80M1 was approximately 4.2 times less than the maximum one in the non-modified AZ80 alloy. However, with the further addition of Y up to 0.4 and $0.8 \mathrm{wt}$ \%, a slightly increased $k$ value was found. This rise may be attributed to the change of liquid phase fraction, as shown in Table 2. Usually, the particle growth also depends on diffusion or flow of solute atoms between the solid particles of different sizes. The experimental results were similar to the results observed by Ferrante et al. [34] and Manson-Whitton et al. [35]. They reported that either the compressed or the spray formed $\mathrm{Al}-4 \mathrm{Cu}$ (wt. \%), and the increase in the quantity of liquid fraction could accelerate the coarsening rate of solid particles during the isothermal treatment because the liquid could provide a much faster diffusion path than the solid. In cases where the continuous liquid path was formed around the spherical solid $\alpha-\mathrm{Mg}$, the coarsening effect can be accelerated. Considering that mentioned above, the AZ80M1 possesses the superior slow coarsening rate, which could serve as the best semi-solid feedstock for the thixotropic behavior.

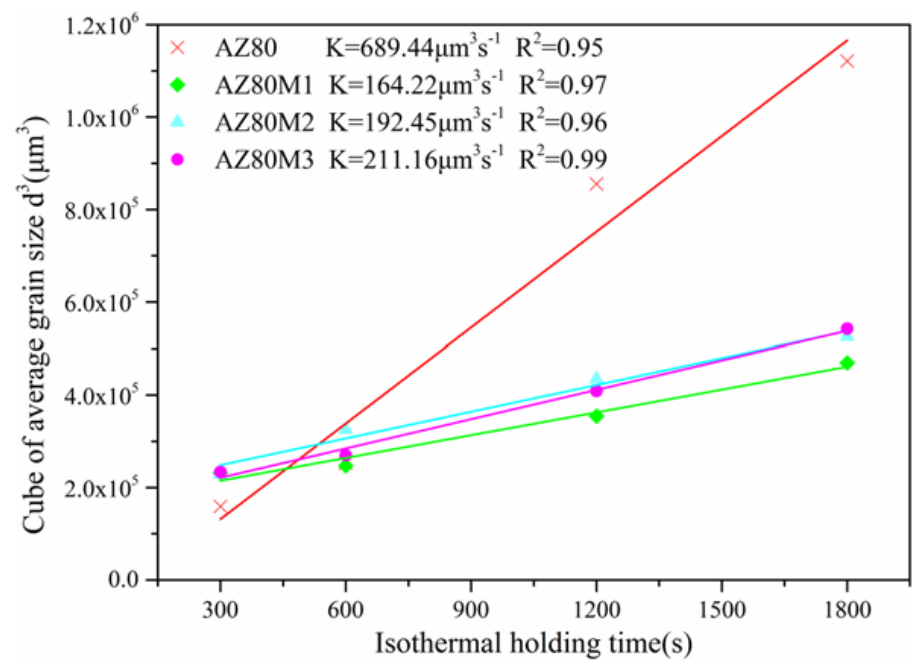

Figure 10. Effect of $\mathrm{Y}$ addition on the coarsening kinetics at $570{ }^{\circ} \mathrm{C}$. 


\section{Conclusions}

In this paper, a semi-solid feedstock of AZ80 magnesium alloy (Mg-8 wt. \% Al-0.5 wt. \% Zn) modified by trace rare-earth $Y$ element $(0,0.2,0.4,0.8 \mathrm{wt}$. \%) was prepared by the SIMA approach by employing the extrusion process. The microstructures' evolution of the extruded and isothermally soaking treated alloys was investigated. The main conclusions can be summarized as follows:

(1) The rare earth element $Y$ had a remarkable effect on the refinement of the microstructure of the AZ80 magnesium alloy during the extrusion process. However, the agglomeration of $\beta-\mathrm{Mg}_{17} \mathrm{Al}_{12}$ phases appeared in the $\mathrm{Y}$ added alloys, which caused quite an inhomogeneous microstructure at the initial stage of partial remelting.

(2) During the isothermal treatment at $570{ }^{\circ} \mathrm{C}$ for different soaking times, the $\mathrm{Y}$ added alloys had more spheroidal and fine solid grains. The spheroidization of solid grains can be simply explained using the Gibbs-Thompson formula.

(3) Both the coalescence and Ostwald ripening mechanism affected the coarsening of microstructure in the semi-solid slurry. The coarsening rate constants of $689.44 \mu \mathrm{m}^{3} \cdot \mathrm{s}^{-1}, 164.22 \mu \mathrm{m}^{3} \cdot \mathrm{s}^{-1}$, $192.45 \mu \mathrm{m}^{3} \cdot \mathrm{s}^{-1}$ and $211.16 \mu \mathrm{m}^{3} \cdot \mathrm{s}^{-1}$ were obtained in AZ80, AZ80M1, AZ80M2 and AZ80M3 alloy soaked at $570{ }^{\circ} \mathrm{C}$, respectively. It can be seen that the coarsening rate of solid particles decreased significantly through the addition of $Y$ element.

(4) The 0.2 wt. \% Y added AZ80 alloy subjected to the extrusion and subsequent isothermal treatment at $570{ }^{\circ} \mathrm{C}$ for 20-30 min was considered as the optimal semi-solid feedstock, which contained the greater shape factor, the homogeneous solid particles and an appropriate solid fraction.

Acknowledgments: The present research was supported by 2017 key development project of Sichuan Province (No.: 2017GZ0399).

Author Contributions: Gaofeng Quan and Qi Tang conceived and designed the experiment; Qi Tang, Mingyang Zhou and Hao Sun performed the experiment; Qi Tang and Hao Sun analyzed the data; Qi Tang wrote the paper; and Qi Tang, Hao Sun and Mingyang Zhou revised the paper.

Conflicts of Interest: The authors declare no conflict of interest.

\section{References}

1. Huang, X.; Suzuki, K.; Saito, N. Microstructure and mechanical properties of AZ80 magnesium alloy sheet processed by differential speed rolling. Mater. Sci. Eng. A 2009, 508, 226-233. [CrossRef]

2. Guo, F.; Zhang, D.F.; Yang, X.S.; Jiang, L.Y.; Pan, F.S. Strain-induced dynamic precipitation of $\mathrm{Mg}_{17} \mathrm{Al}_{12}$ phases in Mg-8Al alloys sheets rolled at $748 \mathrm{~K}$. Mater. Sci. Eng. A 2015, 636, 516-521. [CrossRef]

3. Jiang, W.Y.; Chen, T.; Wang, L.P.; Feng, Y.C.; Zhu, Y.; Wang, K.F.; Luo, J.P.; Zhang, S.W. Microstructure in the semi-solid state and mechanical properties of AZ80 magnesium alloy reheated from the as-cast and extruded states. Acta Metall. Sin. 2013, 26, 473-482. [CrossRef]

4. Staroselsky, A.; Anand, L. A constitutive model for hcp materials deforming by slip and twinning: Application to magnesium alloy AZ31B. Int. J. Plast. 2003, 19, 1843-1864. [CrossRef]

5. Wang, J.G.; Lin, H.Q.; Wang, H.Y.; Jiang, Q.C. Effects of different processing parameters on the semisolid microstructure of the AZ91D alloy during partial remelting. J. Alloys Compd. 2008, 466, 98-105. [CrossRef]

6. Mansoor, B.; Mukherjee, S.; Ghosh, A. Microstructure and porosity in thixomolded Mg alloys and minimizing adverse effects on formability. Mater. Sci. Eng. A 2009, 512, 10-18. [CrossRef]

7. Chen, D.L.; Sadayappan, K.; Patel, H.A.; Bhole, S.D. Microstructure and tensile properties of thixomolded magnesium alloys. J. Alloys Compd. 2010, 496, 140-148.

8. Wang, C.P.; Tang, Z.J.; Mei, H.S.; Wang, L.; Li, R.Q.; Li, D.F. Formation of spheroidal microstructure in semi-solid state and thixoforming of 7075 high strength aluminum alloy. Rare Met. 2015, 34, 710-716. [CrossRef]

9. Tzimas, E.; Zavaliangos, A. A comparative characterization of near-equiaxed microstructures as produced by spray casting, magnetohydrodynamic casting and the stress induced, melt activated process. Mater. Sci. Eng. A 2000, 289, 217-227. [CrossRef] 
10. Wang, C.L.; Chen, A.; Zhang, L.; Liu, W.C.; Wu, G.H.; Ding, W.J. Preparation of an Mg-Gd-Zn alloy semisolid slurry by low frequency electro-magnetic stirring. Mater. Des. 2015, 84, 53-63. [CrossRef]

11. Binesh, B.; Aghaie-Khafri, M. Phase Evolution and Mechanical Behavior of the Semi-Solid SIMA Processed 7075 Aluminum Alloy. Metals 2016, 6, 42. [CrossRef]

12. Haghdadi, N.; Zarei-Hanzaki, A.; Heshmati-Manesh, S.; Abedi, H.R.; Hassas-Irani, S.B. The semisolid microstructural evolution of a severely deformed A356 aluminum alloy. Mater. Des. 2013, 49, 878-887. [CrossRef]

13. Binesh, B.; Aghaie-Khafri, M. Microstructure and texture characterization of 7075 Al alloy during the SIMA process. Mater. Charact. 2015, 106, 390-403. [CrossRef]

14. Zhang, Q.Q.; Cao, Z.Y.; Zhang, Y.F.; Su, G.H.; Liu, Y.B. Effect of compression ratio on the microstructure evolution of semisolid AZ91D alloy. J. Mater. Process. Technol. 2007, 184, 195-200. [CrossRef]

15. Jiang, J.F.; Lin, X.; Wang, Y.; Jian-Jun, Q.U.; Luo, S.J. Microstructural evolution of AZ61 magnesium alloy predeformed by ECAE during semisolid isothermal treatment. Trans. Nonferr. Met. Soc. China 2012, 22, 555-563. [CrossRef]

16. Xu, Y.; Hu, L.X.; Jia, J.B.; Xu, B. Microstructure evolution of a SIMA processed AZ91D magnesium alloy based on repetitive upsetting-extrusion (RUE) process. Mater. Character. 2016, 118, 309-323. [CrossRef]

17. Kleiner, S.; Beffort, O.; Uggowitzer, P.J. Microstructure evolution during reheating of an extruded Mg-Al-Zn alloy into the semisolid state. Scr. Mater. 2004, 51, 405-410. [CrossRef]

18. Liu, L.; Yuan, F.; Zhao, M.; Gao, C.; Feng, P.; Yang, Y.; Yang, S.; Shuai, C. Rare Earth Element Yttrium Modified Mg-Al-Zn Alloy: Microstructure, Degradation Properties and Hardness. Materials 2017, 10, 477. [CrossRef] [PubMed]

19. Tekumalla, S.; Seetharaman, S.; Almajid, A.; Gupta, M. Mechanical Properties of Magnesium-Rare Earth Alloy Systems: A Review. Metals 2015, 5, 1-39. [CrossRef]

20. Nami, B.; Shabestari, S.G.; Miresmaeili, S.M.; Razavi, H.; Mirdamadi, S. The effect of rare earth elements on the kinetics of the isothermal coarsening of the globular solid phase in semisolid AZ91 alloy produced via SIMA process. J. Alloys Compd. 2010, 489, 570-575. [CrossRef]

21. Son, H.T.; Kim, Y.H.; Kim, T.S.; Lee, S.H. Mechanical Properties and Fracture Behaviors of the As-Extruded Mg-5Al-3Ca Alloys Containing Yttrium at Elevated Temperature. J. Nanosci. Nanotechnol. 2016, 16, 1806. [CrossRef] [PubMed]

22. Chen, X.H.; Yan, H. Constitutive behavior of $\mathrm{Al}_{2} \mathrm{O}_{3 \mathrm{np}} / \mathrm{Al} 7075$ composites with a high solid fraction for thixoforming. J. Alloys Compd. 2017, 708, 751-762. [CrossRef]

23. Cai, Z.; Chen, F.; Ma, F.; Guo, J. Dynamic recrystallization behavior and hot workability of AZ41M magnesium alloy during hot deformation. J. Alloys Compd. 2016, 670, 55-63. [CrossRef]

24. Huang, X.; Chino, Y.; Yuasa, M.; Uedab, H.; Inoueb, M.; Kidoc, F.; Matsumotoc, T. Microstructure and mechanical properties of AZX912 magnesium alloy extruded at different temperatures. Mater. Sci. Eng. A 2017, 679, 162-171. [CrossRef]

25. Zhu, Q.F.; Wang, G.S.; Zhang, E.G.; Liu, F.Z.; Zhang, Z.Q.; Cui, J.Z. Dynamic and Static Aging Precipitation of $\beta-\mathrm{Mg}_{17} \mathrm{Al}_{12}$ in the AZ80 Magnesium Alloy During Multi-directional Forging and Subsequent Aging. Acta Metall. Sin. 2017, 30, 941-948. [CrossRef]

26. Robson, J.D.; Henry, D.T.; Davis, B. Particle effects on recrystallization in magnesium-manganese alloys: Particle-stimulated nucleation. Acta Mater. 2009, 57, 2739-2747. [CrossRef]

27. Mezbahulislam, M.; Mostafa, A.O.; Medraj, M. Essential Magnesium Alloys Binary Phase Diagrams and Their Thermochemical Data. J. Mater. 2014, 2014, 33.

28. Li, P.; Chen, T.; Zhang, S.; Guan, R. Research on Semisolid Microstructural Evolution of 2024 Aluminum Alloy Prepared by Powder Thixoforming. Metals 2015, 5, 547-564. [CrossRef]

29. Chen, T.J.; Ma, Y.; Li, Y.D.; Lu, G.X.; Hao, Y. Microstructural evolution of equal channel angular pressed AZ91D magnesium alloy during partial remelting. Mater. Sci. Technol. 2013, 26, 1197-1206. [CrossRef]

30. Tzimas, E.; Zavaliangos, A. Evolution of near-equiaxed microstructure in the semisolid state. Mater. Sci. Eng. A 2000, 289, 228-240. [CrossRef]

31. Nayyeri, M.J.; Khomamizadeh, F. Effect of RE elements on the microstructural evolution of as cast and SIMA processed Mg-4Al alloy. J. Alloys Compd. 2012, 509, 1567-1572. [CrossRef]

32. Loué, W.R.; Suéry, M. Microstructural evolution during partial remelting of Al-Si7Mg alloys. Mater. Sci. Eng. A 1995, 203, 1-13. [CrossRef] 
33. Atkinson, H.V.; Liu, D. Microstructural coarsening of semi-solid aluminium alloys. Mater. Sci. Eng. A 2008, 496, 439-446. [CrossRef]

34. Ferrante, M.; Freitas, E.D. Rheology and microstructural development of a Al-4wt.\%Cu alloy in the semi-solid state. Mater. Sci. Eng. A 1999, 271, 172-180. [CrossRef]

35. Manson-Whitton, E.D.; Stone, I.C.; Jones, J.R.; Grant, P.S.; Cantor, B. Isothermal grain coarsening of spray formed alloys in the semi-solid state. Acta Mater. 2002, 50, 2517-2535. [CrossRef] 